Puede citar este artículo como:

Fábregas García, Adela. «El reino nazarí de Granada como área de comercio internacional: ¿Colonia mercantil o espacio de integración?». Anales de la Universidad de Alicante. Historia Medieval, N. 18 (2012-2014): 153-169, DOI:10.14198/medieval.2012-2015.18.05

\title{
EL REINO NAZARÍ DE GRANADA COMO ÁREA DE COMERCIO INTERNACIONAL: ¿COLONIA MERCANTIL O ESPACIO DE INTEGRACIÓN?
}

\author{
Adela Fábregas García ${ }^{1}$ \\ Universidad de Granada
}

\section{RESUMEN}

El reino nazarí de Granada muestra entre los rasgos más notables de su caracterización socio-económica una marcada orientación comercial de parte de su economía productiva. A través de la misma se proyecta hacia los mercados internacionales, en particular hacia una plataforma de mercados integrados que se está definiendo en esos momentos en el área del Occidente bajomedieval. Así es como se explica la presencia constante y en ascenso de grupos y comunidades de hombres de negocios extranjeros en tierras nazaríes. En este sentido, cada vez se percibe con más claridad la sensación de que nos encontramos ante una realidad próxima a procesos de convergencia, con sus dificultades, éxitos y fracasos, de un mercado que está naciendo y que se está integrando en un espacio económico nuevo, definido como precapitalista.

En todo caso, lo verdaderamente importante en el futuro será calibrar la verdadera dimensión de este viraje que experimenta la estructura económica nazarí de manos de esta orientación especulativo-comercial, y qué grado de distorsión introduce en los principios caracterizadores de lo que se entiende como sociedad islámica clásica.

Palabras clave: Al-Andalus. Reino nazarí. Comercio internacional. Génova. Azúcar. Cerámica.

1 Doctora en Historia. Profesora titular. Departamento de Historia Medieval y Ciencias y Técnicas Historiográficas. Facultad de Filosofía y Letras. Universidad de Granada. Campus Universitario Cartuja 18071 Granada. C.e: fabregas@ugr.es 


\begin{abstract}
The Narsi Kingdom of Grenade shows among the most notable features of its social and economic characterization a pronounced trade orientation in its productive economy. Thus, the territory projects itself on the international markets, particularly on the platform of integrated markets that is being defined in Late Medieval West. That is how we explain the constant and growing presence of groups and communities of foreign trade and businessmen on Nasri soil. In this sense, we perceive with more and more clarity the feeling that we are facing a reality close to convergence processes, with its difficulties, its successes and its failures, of a rising market that is integrating itself in a new economic space, defined as precapitalist.

In any case, in the future the important issue will be to weigh-up the real dimension of this turn that takes place in the economic Nasri structure, led by this speculative-commercial orientation, and what degree of distortion it introduces in the characterizing principles of what we understand as classic Islamic society.
\end{abstract}

Keywords: Al-Andalus, Nasrid Kingdom, International trade, Genoa, Cane Sugar, Pottery.

El reino nazarí de Granada muestra entre los rasgos más notables de su caracterización socio-económica una marcada orientación comercial de parte de su economía productiva. A través de la misma se proyecta hacia los mercados internacionales, en particular hacia una plataforma de mercados más o menos integrados que se está definiendo en esos momentos en el área del Occidente bajomedieval.

Este pequeño reducto islámico se ve implicado, es arrastrado como parte inseparable de todo un sistema de equilibrio y relación de fuerzas que se está constituyendo en el área del Mediterráneo occidental y que se incluye en una dinámica económica de crecimiento y expansión generalizada de la que, pese a ser fundamentalmente ajeno en su origen, naturaleza y protagonismo, no parece poder substraerse el reino nazarí. Por cuestiones de estrategia política ya parece, desde su creación, un reino abocado al comercio, obligado a asumir como vía de supervivencia política la utilización de su potencialidad como espacio de desarrollo de las potencias comerciales occidentales. El reino nazarí no tiene más opción, como no la tiene ninguno de los estados del área, que ser un mercado. Es una realidad comprendida y asumida por el poder nazarí como única vía de supervivencia, no sólo geopolítica, y un camino por el cual debe de conducir al resto de la sociedad nazarí. Y por otro 
lado, como veremos más adelante, el momento en que se encuentra la propia economía nazarí resulta propicio para dar este salto cualitativo.

No sorprende por tanto la dinámica en la que se embarca este pequeño estado del Mediterráneo, que una vez que ha abierto y explora esta vía de desarrollo, no dejará ya de apoyar oficialmente su progresión.

Puede ser interesante para las autoridades nazaríes dejar en manos de los extranjeros este sector internacional del comercio. Lo primero que hacen es facilitar el acceso de los mismos a sus tierras. El esfuerzo constructivo que realiza el estado nazarí y que auspicia, desde mediados del siglo XIV, la creación de un conjunto de infraestructuras necesarias para el desarrollo satisfactorio de contactos y de actividades de intercambio, es el vestigio material más evidente de esta apuesta ${ }^{2}$. Es muy patente también la progresiva apertura por parte de las autoridades nazaríes a un espectro cada vez más amplio y diversificado de comunidades mercantiles, a las que se atrae, entre otras cosas, con un trato fiscal favorable.

Así es como se explica la presencia constante y en ascenso de grupos y comunidades de hombres de negocios extranjeros en tierras nazaríes. Entre estas comunidades destaca el grupo genovés, sobresaliente por la duración de su presencia y por la dimensión de sus negocios, aunque ni mucho menos los únicos que trabajan el mercado nazarí. En todo caso si que es cierto que la calidad de los rastros que dejó su presencia nos lleva a utilizar de manera preferente su caso en nuestra exposición.

Son ya bien conocidos en su mayoría los rasgos más destacados de la actuación genovesa en territorio nazarí, y hemos de decir que, los pocos trazos que aún conocemos acerca de la actuación de otras comunidades extranjeras los acercan mucho a las características de este grupo destacado. Vale la pena recordarlos brevemente y en su caso detallar algo más los peor conocidos:

- Interés por una serie de artículos definidos. En Granada los hombres de negocios europeos buscan bienes muy determinados, marcados en la mayor parte de los casos por su carácter aún exótico y vinculado a la esfera del lujo en el mercado de consumo occidental. Pero, sobre todo, marcados por una dificultad aún insuperable para su aprovisionamiento en otros puntos del área. La seda y el azúcar de caña ilustran perfectamente lo que decimos. La planta de la que se extrae el azúcar, la caña dulce, tiene unas exigencias

2 La identificación de programas constructivos que hacen patente de una forma más contundente la presencia del Estado nazarí en todos los rincones del reino es sugerida por MALPICA CUELLO A., Entre la arqueología y la historia. Castillos y poblamiento en Granada. Estudio de una política edilicia a partir de la Alhambra, en XXII Semana de Estudios Medievales. Estella 1995. Tecnología y Sociedad: Las grandes obras públicas en la Europa Medieval, Pamplona, 1996, pp. 289-326. 
medioambientales muy estrictas, que restringen su presencia en la franja del Mediterráneo occidental. La planta, de origen tropical, tiene su factor de limitación corológica más determinante en la temperatura. No puede sobrevivir en temperaturas más bajas de $21^{\circ}$ centígrados, de manera que el frío invernal que se da en la mayor parte de nuestra zona, y sobre todo la posibilidad de heladas extremas o tardías, ya iniciado el ciclo vegetativo de la planta, son letales. Sólo el carácter marítimo de ciertas zonas mediterráneas podría paliar de manera importante los déficits locales del clima en este sentido. Por otro lado sus exigencias hídricas (la caña de azúcar requiere al menos una media de precipitaciones anuales de $1.200-2.000 \mathrm{~mm}$ ) resultan menos problemáticas de cubrir en zonas donde, a estas alturas, está ya plenamente integrada la tradición agrícola islámica que se desarrolla a partir de los sistemas de irrigación artificial. De manera que sólo a niveles ecológicos la presencia de la planta ya está extraordinariamente limitada en el Mediterráneo occidental a muy contadas zonas costeras del sur y levante de la Península Ibérica, y a las islas mediterráneas (Sicilia, Mallorca).

A ello se añade una nueva dificultad: la complejidad técnica de su elaboración, que supondría una limitación definitiva en estos momentos. Los pasos que se han de cumplir para la manipulación de la planta, la extracción de su jugo dulce y la elaboración posterior del mismo hasta su transformación en granos de azúcar, construyen un proceso técnico complejo, cuyos secretos quedan en manos de pocos conocedores, pocos maestros azucareros, que beben de la tradición tecnológica islámica que ha creado este procedimiento sofisticado. Así que, a estos pocos espacios donde puede vivir la planta en el Mediterráneo occidental habríamos de restar los que en todo caso no sabrían qué hacer con la misma y que por tanto no la implantan hasta que no accedan al conocimiento y uso satisfactorio de sus técnicas de manipulación.

Eso explica en buena medida que las tierras de la costa del pequeño reino nazarí sean de las pocas que están en disposición de ofrecer, con unas condiciones, además, de mercado muy satisfactorias, el azúcar de caña, cada vez más valorado por el gusto occidental. Su aprovisionamiento es uno de los objetivos principales para estos hombres de negocios.

Igual sucede con la seda, que se busca en su calidad de materia prima con la que abastecer la naciente industria sérica que se desarrolla en todo el Mediterráneo. En este caso, la obtención del artículo parece menos problemática en la región, y sin embargo la creciente demanda de materia prima a manos de una industria sérica próspera en Europa, garantiza el interés foráneo por la seda nazarí, tanto más cuando, al parecer, goza de una cierta reputación. La introducción de maquinaria hidráulica en Italia sustenta un aumento de 
la producción importante que genera una demanda de materia prima, de seda cruda, importante ${ }^{3}$. Pero la demanda procede de todos los frentes. También Valencia, que muestra una resistencia a la incorporación de nuevos avances técnicos que aumentaran esta productividad ${ }^{4}$, está tan interesada en hacerse con la materia prima granadina, particularmente valorada, que no duda en poner en marcha estrategias para el aprovisionamiento en régimen de monopolio de la misma a partir de $1415^{5}$.

- La demanda internacional de estos y otros artículos supone un enorme refuerzo que se da a sectores productivos como el sedero o el azucarero. En este caso nuevamente el ejemplo que mejor conocemos hasta el momento es el del azúcar. Su exportación la gestionan mercaderes italianos, genoveses concretamente, a través de una sociedad de explotación conocida como Sociedad de La Fruta ${ }^{6}$ y liderada por la poderosa familia Spinola. Su peso en el mundo de los negocios internacional y las estrechas relaciones que mantienen con los círculos de poder nazaríes, les permiten disfrutar de unas condiciones absolutamente ventajosas, que nos llevan casi a poder hablar de una explotación en régimen de monopolio, a pesar de que formalmente no esté constituida como tal. En todo caso la implicación en el negocio azucarero granadino y la presencia de la familia en Europa, hacen que el azúcar y los frutos secos nazaríes estén presentes y sean fuertes en los principales mercados europeos.

No conocemos con exactitud el momento de constitución de esta sociedad, aunque sí sabemos que está ya operativa al menos desde 1378 y que todavía está funcionando casi un siglo después, en 1460. Actúa a través de delegados en los principales puntos de recogida del producto y exportación, los gobernadores, destacados al menos en Málaga y Almuñécar. Ellos son los que dirigen todas las operaciones de aprovisionamiento de fruta seca y azú-

3 NAVARRO ESPINACH G., "El arte de la seda en el Mediterráneo medieval", en En la España medieval 27, Madrid 2004, pp. 5-51, espec. pp. 17 y ss.

4 Idem, p. 18.

5 SALICRÚ I LLUCH R., "La Corona de Aragón y Génova en la Granada del siglo XV", en FERRER I MALLOL M.T. y COULON D. (eds.), L'expansió catalana a la Mediterrània a la Baixa Edat Mitjana, Barcelona, 1999, pp. 121-144.

6 No entramos ahora en los detalles acerca del funcionamiento y ámbito de actuación de la misma. Remitimos a los trabajos de HEERS J., "Le Royaume de Grenade et la politique marchande de Gênes en Occident (Xve siècle)", en Le Moyen Age, 1957, pp. 87-121; LÓPEZ DE COCA J.E., "La Ratio Fructe Regni Granate. Datos conocidos y cuestiones por resolver", en Aragón en la Edad media: rentas, producción y consumo en España en la baja edad media, Zaragoza, 2000, pp. 121-131; FÁBREGAS GARCÍA A., "Vías de acceso del azúcar del reino de Granada al mercado europeo: La Sociedad de los Frutos (Siglos XIV-XV)", en Actas del Segundo Seminario Internacional de la Caña de Azúcar. História do açúcar. Rotas e mercados, Madeira, 2002, pp. 23-54. 
cares, que compran a los productores locales a través de diversas fórmulas, incluida por supuesto la compra por adelantado de partidas importantes. Para ello cuentan con la ayuda inestimable de interlocutores locales de su plena confianza e integrados dentro del organigrama operativo de la sociedad, los llamados colectores. Así reúnen cada año un volumen de mercancía notable que embarcan en sus propias naves, las naves de la fruta, y que se preocupan por enviar a los mercados en mejor disposición del momento, aprovechando para ello la nutrida red de contactos e informadores con que cuentan por toda Europa.

Una de las cosas interesantes a la hora de explicar la rentabilidad del negocio, y por tanto su prosperidad y duración, es la capacidad que muestran los Spinola para regir su actuación a partir de un criterio básico de oportunidad, lo que les permite ser extraordinariamente competitivos frente a otros azúcares de mejor calidad, o que quizás puedan presentarse en cantidades mayores que las permitidas por el sistema productivo nazarí. De hecho, aún sin ser particularmente abundantes, ni particularmente buenos, los azúcares nazaríes pueden, consiguen en algunos momentos, inundar mercados tan importantes como Brujas, bloqueando a eventuales competidores, sólo porque llegaron en el momento oportuno. Las situaciones de zozobra a que lleva esta habilidad genovesa son bien conocidas por los demás mercaderes europeos, que mueven sus productos en función de las informaciones que les llegan acerca de los movimientos de los Spinola. Esta estrategia, junto a la posibilidad de ampliar de manera considerable el espectro de mercado del hasta entonces elitista azúcar, gracias a la introducción de calidades inferiores, ofrecen una rentabilidad al grupo genovés que garantiza la demanda continuada de estos productos.

- Su interés por obtener artículos de difícil acceso en condiciones beneficiosas que hagan su esfuerzo rentable puede subyacer también en la promoción de ciertas industrias en la zona, llegando probablemente a participar en procesos de transferencia productiva. De hecho no es una novedad la consideración del mercado y de la presión constante que ejerce, como uno de los más potentes agentes que condicionan la estructura de secuencias tecnológicas y de procesos productivos determinados ${ }^{7}$.

Evidentemente no entraremos en un tema complejo, que implica detenernos en cuestiones tan delicadas como las relativas a modificaciones de la estructura productiva de espacios receptores de nuevas prácticas; sobre todo

7 Así lo expresan con rotundidad, por ejemplo, CALEGARI M., "Nel mondo del pratici: molte domande e qualche risposta", en Saper fare. Studi di storia delle tecniche in area mediterranea, Cagliari, 2004, pp. 9-33; NAVARRO ESPINACH G., "El arte de la seda en el Mediterráneo medieval", en En la España medieval, 27 (2004), pp. 5-51, espec. p. 6. 
cuando éstas implican una reorientación de parte de la base económica de la zona hacia producciones especulativas. Tampoco estamos en condiciones de abordar el análisis de procesos de migración, por el momento no estudiados en el caso granadino y que tan importantes resultan a la hora de emprender estudios sobre transferencias tecnológicas y productivas. No podemos ofrecer argumentos sólidos que sostengan o detallen de manera suficiente datos conocidos y constatados. Datos que apuntan hacia la participación del mundo mercantil en estos procesos de transferencias de ciertas producciones destinadas al mercado. Pero sí que adivinamos su estímulo e incluso su participación en esta reorientación especulativa de parte de la economía nazarí.

En este sentido nos podemos referir, por ejemplo, a la introducción en Granada, bastante temprana, por cierto, de algunas producciones de clara vocación comercial y que de hecho se convertirán en tarjetas de presentación de Granada en el mercado internacional. A pesar de las dificultades e incertidumbres que comporta siempre el tratamiento de cuestiones de este tipo, hay un caso que se puede rastrear de manera razonablemente satisfactoria. Se trata de las cerámicas de lujo, que no son, desde luego, materia de comercio prioritario en el mercado internacional nazarí, pero que aún así encuentran su espacio en el mismo. Su valor tiene que ver con el carácter imperecedero de sus restos, que permiten un rastreo certero de su secuencia tecnológica y una reconstrucción de sus arterias de circulación internacional, que nos permiten concluir ciertos vínculos.

Es el caso de la cerámica azul y dorado, cerámica de lujo, fácilmente identificable como nazarí a nivel internacional, donde goza de cierta reputación en los sectores más altos del mercado. Esta producción es una novedad en Al-Andalus desde el s. XIII a partir de su aparición precisamente en nuestra zona. Donde se presenta por primera vez casi en el mismo momento, poco después, de constitución oficial de este pequeño estado. El precedente tecnológico y estilístico más cercano de la misma procede del norte de Túnez, concretamente de la cerámica cobalto y manganeso ${ }^{8}$ que elaboran allí los artesanos tunecinos y que ya en el siglo XII exportan a toda Europa los mercaderes genoveses que gozan de una sólida implantación en la zona. De allí, a tenor de las similitudes técnicas y estilísticas constatadas, debe de proceder9.

8 GARCÍA PORRAS A., "Los orígenes de la cerámica nazarí decorada en azul y dorado", en Atti XXXV Convegno Internazionale della Cerámica, Firenze, 2003, pp. 52-63.

9 GARCÍA PORRAS A., "Transmisiones tecnológicas entre el área islámica y cristiana en la Península Ibérica. El caso de la producción de cerámica esmaltada de lujo bajomedieval (ss. XIII-XV)", en CAVACIOCCHI S. (a cura di), Relazioni economiche tra Europa e mondo islámico secc. XIII-XVIII. Atti della Trentottesima Settimana di Studi, 1-5 maggio 2006, Firenze, 2007, pp. 827-843. 
La transmisión de las técnicas de elaboración asociadas a la misma, de extraordinaria complejidad, deben de pasar por un desplazamiento en uno $\mathrm{u}$ otro sentido de artesanos y en todo caso por un asentamiento en tierras nazaríes de manipuladores acreditados de esta técnica que soporten su introducción efectiva. Desgraciadamente este proceso no ha podido ser confirmado con datos concretos, que vayan más allá de algunas pistas fugaces, como la que nos ofrece la presencia de una mezquita de un tunecino en la Granada del siglo $\mathrm{XV}^{10}$, que nos ayudaría a confirmar la presencia de una comunidad de este origen en territorio nazarí. En todo caso si que se conoce la vigencia de contactos estrechos entre los dos espacios, con una tradición ya para entonces secular. Los vínculos económicos entre Túnez y Al-Andalus son sólidos y mantenidos en el tiempo. Todo indica que Túnez actuaba ya al menos desde s. XII como eje de conexión entre los mercados de Oriente y Occidente mediterráneo. Hasta allí se desplazan al parecer mercaderes andalusíes para vender sus productos, consumidos por el mercado tunecino o reexportados posteriormente, y allí se surtían de otros artículos orientales, como especias o lino sirios y egipcios. Sabemos, por ejemplo, de la centralidad de Túnez como destino de exportación de la seda andalusí, y sobre todo conocemos la función de redistribución de esta seda hacia mercados orientales, egipcios, que asumen los comerciantes tunecinos en esas fechas, según confiesan los autores de la correspondencia cairota de la Genizál ${ }^{11}$.

Y sabemos también de la presencia de comunidades consolidadas de andalusíes en Túnez, constante y destacable desde mediados del siglo XIII, hasta el punto de que Bruschvig recuerda la existencia de comunidades oficialmente constituidas, con representantes y líderes de las mismas reconocidos como tales, en Bujía, por ejemplo, o la no improbable existencia de una pequeño barrio andalusí en Qayrawan ${ }^{12}$, y por supuesto en la capital, Túnez. Su integración en el tejido social y económico hafsí se completa sin dificultades, desarrollando todo tipo de actividades, incluyendo las mercantiles y artesanales, aunque conservan rasgos propios y un sentimiento de solidaridad hacia sus compatriotas. Es pues, razonable pensar que existan este tipo

10 RODRÍGUEZ GÓMEZ M.D., "Documentos notariales árabes sobre almacerías", en Revista del centro de Estudios Históricos de Granada y su Reino, Segunda Época 19 (2007), pp. 217-258, espec. pp. 243-244.

11 GOITEIN S. D., A mediterranean society. The jewish communities of the World as portrayed in the documents of the Cairo Geniza, vol. I, Los Angeles 19992, p. 214. La seda andalusí goza de una buena distribución en mercados egipcios como Alejandría. Idem, p. 303.

12 BRUNSCHVIG R., La Berbérie orientale sous les Hafsides. Des origines a la fin du XVe siècle, Paris 1947, t. II, pp. 155-156. 
de intercambios productivos y tecnológicos, ya adivinados en otro tipo de producciones cerámicas, como los azulejos ${ }^{13}$.

Pero insistimos, más allá de intuirla y darla por probable, por el momento no podemos confirmar con más detalles la existencia de una comunidad tunecina en el reino nazarí, y mucho menos vincularla a ciertos sectores artesanales, aunque quede también claro el éxito de este proceso de transferencia productiva. Y desde luego adivinamos que tras el mismo pueden subyacer los intereses de los principales implicados comerciales de este sector. Esos comerciantes italianos, activos y operativos en el mercado tunecino, que adornan sus iglesias y sus casas con esta cerámica entre finales del siglo XII y mediados del XIII, que la llevan por toda Europa y que después la sustituyen con esta cerámica nazarí, que logran introducir en los circuitos internacionales de artículos de lujo ${ }^{14}$. Las dificultades que encuentran en estos momentos en el mercado tunecino ${ }^{15}$, pueden ser corregidas precisamente con la apertura de nuevas oportunidades, como ésta que les ofrece el mundo nazarí. Y no podemos excluir que impulsen la transferencia de sectores productivos como éste de la cerámica de lujo destinada a la exportación a zonas desde las que pretenden operar a partir de entonces. De todos modos, y sin entrar en detalles, no constituiría una novedad, teniendo en cuenta que el mismo proceso se sabe con más certezas que se repetirá posteriormente con la introducción a partir del siglo XIV de este tipo cerámico en los alfares valencianos con el claro concurso de la iniciativa mercantil ${ }^{16}$. De todos modos este punto queda por el momento solamente perfilado, casi intuido.

- Así que pueden incentivar, propiciar o apoyar la introducción de nuevos sectores productivos de carácter especulativo en el tejido económico local. Llegan, incluso, a forzar continuamente, el horizonte productivo de una tierra que, seguramente, roce el límite de su capacidad. Pero no llegan a más. Su capacidad invasiva en el conjunto de la economía nazarí se detiene aquí. De hecho la faceta especulativa del mundo nazarí encuentra un freno definitivo en un tejido productivo que no puede, o no quiere, ir más allá.

Una circunstancia frente a la que estos hombres de negocios muestran escaso margen de maniobra, ya que, a pesar de todo, los grupos mercanti-

13 BRUNSCHVIG R., La Berbérie orientale..., p. 233.

14 GARCÍA PORRAS A., "La cerámica española importada en Italia durante el siglo XIV. El efecto de la demanda sobre una producción cerámica en los inicios de su despegue comercial", en Archeologia Medievale, XXVII (2000), pp. 131-144, espec. pp. 133-135.

15 JEHEL G., L'Italie et le Maghreb au Moyen Age. Conflicts et échanges du VIIe au XVe siècle, Paris 2001.

16 GARCÍA PORRAS A., La cerámica en azul y dorado valenciana del siglo XIV e inicios del XV, Valencia 2008. 
les extranjeros no habrían logrado involucrarse directamente en el sistema productivo. Efectivamente, con dificultad, de manera casi excepcional hasta el momento, se constata una participación directa en los procesos productivos por parte de los capitales extranjeros vinculados al comercio. Los libros de contabilidad de varios mercaderes genoveses miembros, precisamente de esa familia Spinola, personajes relevantes en el mundo de los negocios granadinos y que se mostrarían como individuos idóneos para protagonizar ese salto cualitativo tan sustancial en la práctica económica, dadas sus excelentes relaciones con la Corona nazarí, no dejan en sus cuentas señales de ningún tipo de propiedad, agraria ni industrial, en tierras nazaríes. El testamento de uno de ellos, Francesco Spinola, también conservado y que da buena cuenta de todas sus propiedades en el momento de su muerte, es claro en este sentido. No hay rastro de propiedades vinculadas al ámbito productivo, agrario, artesanal o de cualquier otro tipo, propias ni ajenas, de los muchos amigos y colaboradores que aparecen reflejados en sus cuentas. Tampoco la escasa documentación que conocemos acerca de la propiedad de tierras o de plataformas de transformación de azúcar en época nazarí, ni siquiera en los momentos finales de existencia del reino, cuentan en ningún caso con propietarios extranjeros, ni con copropietarios, como ocurre más adelante, ni con gestores. No hay rastro de ellos.

En cuanto a los frutos secos, nos los encontramos siempre comprándolos a productores locales, en ningún caso recogiendo o gestionando sus propias cosechas. Y tanto de lo mismo se puede decir respecto a lo poco que conocemos acerca de la seda, para la que muestran un modelo de actuación muy similar al explicado en el caso del azúcar ${ }^{17}$. El objetivo prioritario del extranjero se centra en la adquisición de la materia prima a unos intermediarios locales que forman parte del cuerpo mercantil indígena. La distancia que separa al mercader extranjero del productor de seda nazarí está fuera de toda duda. Y mucho más una eventual participación o control directo de los procesos productivos, absolutamente excluidos por el momento.

Conocemos cesiones de propiedades a mercaderes genoveses en tierras nazaríes, sí. Pero son absolutamente excepcionales, por las circunstancias en que se desarrollan, como recompensa a apoyos estratégicos realizada por la

17 FÁBREGAS GARCÍA A., "Aprovisionamiento de la seda en el reino nazarí de Granada. Vías de intervención directa practicadas por la comunidad mercantil genovesa", en En la España Medieval, Universidad Autónoma de Madrid, 27 (2004), pp. 53-75. 
misma casa nazarí, y por la entidad de la propiedad ${ }^{18}$. De manera que a día de hoy podemos decir que, efectivamente, no participan.

Y no por falta de interés, desde luego. Los genoveses no dudan en apoyar la introducción de caña dulce, por ejemplo, en nuevos espacios productivos, quizás más abiertos a ka reorientación de esta actividad hacia fórmulas de cultivo más intensivas. Agotada o nunca culminada la posibilidad de una implicación directa del capital genovés en la producción de azúcar nazarí, no dudan en embarcarse en esta nueva faceta como productores allá donde se les permita ${ }^{19}$. Y podemos encontrar también a los genoveses rápidamente dispuestos a participar en la producción de azúcar granadina, en cuanto se les deja, eso sí, inmediatamente después de la conquista castellana ${ }^{20}$.

- Esta circunstancia remite a una realidad constatada a otros niveles. Las pocas noticias que tenemos acerca de la vida de estos hombres de negocios en Granada trasluce un deseo de provisionalidad y segregacionismo marcados ${ }^{21}$. Su vida cotidiana transcurre aquí, una vez que termina la jornada, encerrada en los estrechos límites de la comunidad extranjera, ajena al conjunto de

18 La propiedad a que nos referimos, un unicum en la historia nazarí conocida hasta el momento, remite a Gregorio Spinola, que se suma a la causa de Muhammad VIII el Pequeño frente a su contendiente Muhammad el Zurdo. En reconocimiento a este apoyo se le concede la posibilidad de comprar una posesión plantada de olivos por precio de 30.000 besantes (quedam possesio olivata posita in territorio Ermerie quam dictus Gregorius emerat et acquisiverat a recolenda memoria serenissimo rege Macometo aben Usef, predecessore vestre maiestatis in regno, de quibus emptione et acquesitione patent publica documenta apud dictum Gregorium existentia de bizantiis triginta milibus ro pretio dicta posessionis...). Propiedad que posteriormente le será expropiada con la misma facilidad por su sucesor y antiguo contrincante. SALICRÚ R., "Génova y Castilla, genoveses y Granada. Política y comercio en el Mediterráneo occidental en la primera mitad del siglo XV (1431-1439)", en AIRALDI G. (a cura di), Le vie del Mediterraneo. Idee, uomini, oggetti (secoli XI-XVI), Génova, 1997, pp. 213-257, doc. XXIV del Apéndice documental, pp. 254-255.

19 En Portugal, por ejemplo, ya a principios del s. XV, y cómo no en las islas Canarias.

20 MALPICA CUELLO A., "Las "tierras del rey" y las ordenanzas de la acequia del río Verde en Almuñécar», en DEL VAL VALDIVIESO I. y MARTÍNEZ SOPENA P. (dirs.), Castilla y el mundo feudal. Homenaje al profesor Julio Valdeón, Valladolid 2009, vol. II, pp. 167-178.

21 Práctica bastante común, por lo general, en los mércados de la órbita islámica del momento. PETTI BALBI G., "Gli insediamenti genovesi nel Nord-Africa durante il “400", en ROSSETTI G. E VITOLO G. (a cura di), Medioevo mezzogiorno mediterraneo. Studi in onore di Mario del Treppo, vol. II, Napoli 2000, pp. 121-137, e IDEM, Las ciudades marítimas italianas y el Norte de África en época medieval: relaciones políticas y económicas». (Italiano-Español), en TRILLO SAN JOSÉ C.(ed.): Relaciones entre el Mediterráneo cristiano y el norte de África en época medieval y moderna, Granada, 2004, pp. 17-51. 
la población indígena. Residen en espacios cerrados, casi fortalezas ${ }^{22}$, las alhóndigas o fanadiq, constituidos por estructuras que agregan y contienen habitaciones y servicios de diverso tipo. Un entorno protegido e incluso algo $a_{\text {asfixiante }}^{23}$, en el que viven comunidades que se empeñan por mantener vivas las propias tradiciones y prácticas de su tierra, sin interés ninguno por integrarse a cualquier nivel con la población indígena. Su resistencia, por ejemplo, a aprender la lengua que fuerza el uso constante de trujamanes ${ }^{24}$, la iglesia con la advocación del patrón nacional o su empeño por mantener prácticas cotidianas en entornos adversos, caso de la ingesta de vino, cuya garantía es tan importante como para ver la necesidad de fijarla en los tratados diplomáticos, nos ponen sobre la pista de esta realidad ${ }^{25}$. En realidad se está trasladando el deseo manifiesto de una segregación neta por ambas partes. Por parte de las autoridades locales, y por parte de las instituciones de la madre patria, que pretenden garantizar el vínculo que los une a sus hombres más emprendedores, auspiciando una cierta temporalidad de las estancias de sus mercaderes en el extranjero.

En general, aunque no parece poder excluirse en casos, eso si, excepcionales en el mundo islámico, la vía de una naturalización que implica una integración plena con el substrato indígena, lo cierto es que el nivel máximo de interacción con la sociedad local podría definirse en el grado de estante (commorante) que algunos de estos mercaderes obtienen en alguna de las sedes nazaríes ${ }^{26}$. Difícilmente superan este grado. Y en este caso su objetivo

22 A tenor del nombre que adoptan en algunos casos (castil de los ginoveses), de la función que asumen con posterioridad (cárcel, en Granada) o de las descripciones que nos llegan de algunos de estos edificios.

23 El florentino Tuccio di Gennaio recuerda, no sin cierto agobio, que «... in verità ci si stà a gran pericolo perche son gente bestiale. Almeno qui non si può chaminare de note, ne simile andarb(i)si diportando per la tera, che subito è sera siamo serati soto chiave; $e$ (...) cisi vita di santi padri, che a me mi pare esere tornato da un pocho in qua romiro per forza...». Archivio di Stato di Prato. Archivio Datini. Filza 893 (Carteggio comune di Malaga), 515432.

24 PELAEZ ROVIRA A., "Sobre el uso de la lengua árabe en el comercio genovés con el Islam occidental bajomedieval", en Atti della Società Ligure di Storia Patria, XLVII (2007), pp. 143-176,

25 El Senado veneciano recuerda a su embajador Bernardo Contarino que en las conversaciones que mantenga en Granada con vistas a la firma de un tratado de paz y comercio con los nazaríes, debe de incluir la posibilidad de que «...consul et mercatores nostri in Malicha existentes et conuersantes possint ponere in fontico ubi morantur vinum et alia victualia pro eorum victu sine solutionem alcunis datii sicut facuint in quibuscumque terris et locis saracenorum in quibus mercantur et conuersantur... ». Archivio di Stato di Venezia, Senato Misti, reg. XLV, fol. 9 r.

26 Benedetto Cattaneo f. Anfreoni es estante en Málaga en 1452, (fol. LXXVI v.); Battista Spinola q. Caroli es estante en Almuñécar en 1451 (fol. LXXV v.); Francesco 
parece ser, única y exclusivamente, responder del mejor modo posible al interés de su negocio, lo que incluye asegurar una presencia capilar por el territorio, gracias a una red de colaboradores desplazados por el mismo, y gracias también a un contacto estrecho con representantes de la red mercantil indígena, actuando, todos ellos, como informadores de las oportunidades y de las posibilidades en cada momento y lugar y proponiéndose por tanto como una buena alternativa a su presencia física en las redes de mercados locales o en los centros productivos. Eso quiere decir que cuentan, que deben de contar, con una red de intercambios local plenamente constituida, dinámica y activa a pleno rendimiento, que es la que permite al comerciante internacional acceder a un mercado nazarí que él no crea. Es ahí, en ese punto, donde se detiene su intervención.

En definitiva, su integración en la realidad económica nazarí se ve muy limitada, desde el momento en que se prueba su recurso a la red mercantil local como intermediarios inexcusables y por supuesto desde el momento en que se entiende su desvinculación absoluta con el tejido productivo indígena del que se nutren. Y por otro lado, completando la lectura de estos datos, se puede afirmar que la economía nazarí mostraba ya unas condiciones internas absolutamente favorables, con un tejido de intercambio propio y constituido y que seguramente es previo a su entrada en la plataforma de intercambios internacional. Desgraciadamente podemos dar pocos detalles más al respecto, y desde luego ésta no es la ocasión adecuada para hacerlo ${ }^{27}$. Bástenos con afirmar su existencia, vigencia y operatividad y con subrayar la absoluta prioridad de su recurso a la hora de proyectar la economía nazarí hacia el exterior a través de su comercio.

Nos interesa subrayarlo porque con ello se completa un cuadro general, que podría resumirse en:

Centurione es estante en Granada en 1451 (fol. LXXV v.), al igual que Cristoforo Judex en 1452 (fol. LXXX v.). FÁBREGAS GARCÍA A., La familia Spinola en el reino nazarí de Granada. Contabilidad privada de Francesco Spinola (1451-1457), Granada 2004.

27 De hecho, su reconstrucción es una de las grandes asignaturas pendientes en el futuro de los estudios nazaríes. Para un avance acerca de las líneas que consideramos importante desarrollar remitimos a un trabajo salido recientemente. FÁBREGAS GARCÍA A., "La vida económica del Sultanato nazarí en su vertiente comercial", en MALPICA CUELLO A., PEINADO SANTAELLA R.G., FÁBREGAS GARCÍA A. (eds.), Historia de Andalucía, VII. Coloquio, Granada 2010, pp. 81-101. 
1. Interés por ciertos productos y capacidad de impulso a los mismos.

2. Incapacidad para penetrar en el tejido productivo indígena.

3. Recurso a una estructura de mercado e intercambio interior ya existente.

A la vista de lo expuesto, el concepto de captación colonial, se entenderá, se ve extraordinariamente minimizado. En este sentido nos atrevemos a hablar de intereses y de espacios complementarios, que no dependientes y ni mucho menos subyugados económicamente, acercándonos más a un contexto de integración de espacios económicos. No hacemos más que sumarnos a quienes defienden el estudio del desarrollo económico de una zona independientemente del impacto que sobre la misma pueda tener el desarrollo espectacular de las actividades de intercambio internacional, que se identificó en su momento con los niveles de una "revolución" comercial". Con ello se atenúa, se matiza el concepto tradicional del desarrollo bajomedieval en una clave centro-periferia, espacios de dominio económico-espacios dominados económicamente, que con cierta facilidad se ha vinculado a las teorías de colonialismo comercial ${ }^{28}$.

Por el contrario, se trata de una realidad más próxima a procesos de convergencia, con sus dificultades, éxitos y fracasos, de un mercado que está naciendo y que se está integrando en un espacio económico nuevo, definido como precapitalista. Granada no es un mero espacio de tránsito, abierto y a merced de gentes extranjeras que proyectan sus intereses en estas tierras, que determinan su futuro y que condicionan su presente económico. Su acceso a esta plataforma de mercado internacional se sustenta en unas condiciones previas de desarrollo interno que son las que hacen posible este salto hacia delante, ofreciendo facilidades y atractivos, pero controlando en todo momento la disponibilidad y grado de apertura de este mercado.

Pero atención. Esto no quiere decir ni mucho menos que este nuevo sistema de relaciones, planteado, si, en términos de menor dependencia que antes, aunque en todo caso marcado por una fuerte mediatización, no suponga un gran revulsivo, o mejor dicho un elemento distorsionante en la configuración de la sociedad nazarí.

De hecho, en el caso concreto del mundo nazarí, la huella de esta presencia puede ser mucho más profunda de lo que se podría pensar. Me explico.

28 Tesis expuestas con brillantez por primera vez de manera global por EPSTEIN S.R., An island for itself. Economic development and social change in late medieval Sicily, Cambridge 1992, aplicadas a su estudio sobre la Sicilia medieval, acogidas de manera inmediata y que dieron lugar a congresos de la talla del celebrado en Valencia en 1994 y publicado poco después con el título El Mediterráneo y la idea de Europa en el tránsito de la Edad Media a la Moderna: espacios, culturas, intercambios, élites. 
Cada vez con más fuerza se viene contemplando la posibilidad de que este pequeño reino islámico represente un estadio evolucionado en la trayectoria del Islam clásico. El mundo nazarí muestra una situación de ruptura del tradicional equilibrio mantenido en las sociedades islámicas clásicas entre las dos grandes fuerzas que las componían, la base social campesina de estructura tribal y el Estado. Lo que ocurre es que parece constatarse un sustancial avance de este último, que va imponiendo su dominio sobre el conjunto de la sociedad, que hasta entonces se habría mostrado refractaria o al menos conservado ciertos espacios de autonomía, sobre todo en el mundo campesino frente a una capacidad de penetración limitada del Estado. Estamos asistiendo a un reforzamiento del poder político, que busca, y encuentra, espacios de tutela directa, a través de los cuales conseguirá controlar sectores muy importantes de la sociedad: lo más evidente es que se hacen con la ciudad, pero además se hacen señores de la religión y penetran en el tejido productivo.

Un ejemplo de cuanto venimos diciendo. Los reyes recuperan la ciudad, que se pretende utilizar como elemento de transmisión y afirmación del poder real, como elemento de cohesión política y de identificación ideológica. En Málaga, o en la misma Granada, por ejemplo, se hegemoniza y en cierta medida se neutraliza el tradicional polimorfismo social de la ciudad. Los rasgos externos de esta nueva estrategia son evidentes ${ }^{29}$. Cambia la configuración urbana y religiosa de la ciudad, con la reunificación de los ejes de poder en torno a núcleos bien definidos, identificables directamente con la figura real, como puede ser el entorno de la mezquita aljama de Granada ${ }^{30}$ o Gibralfaro, en Málaga. El amplio programa urbanístico que emprenden grandes soberanos como Yusuf I o Muhammad V busca plasmar su presencia,

29 CALERO SECALl, I. y MARTíNEZ ENAMORADO V., Málada, ciudad de Al-Andalus, Málaga 1995; MALPICA CUELLO, A., "Granada, ciudad islámica: centro histórico y periferia urbana", en Arqueología y territorio medieval, 1 (1994), pp. 195-208; AA.VV., Ciudad y Arqueología Medieval. Granada, 2006; GARCÍA PORRAS A., "Ocupación del espacio en la orilla izquierda del río Darro. El barrio de San Matías (Granada) “, en CARA L. (ED.), Ciudad y territorio en al-Andalus, Granada, 1999, pp. 111-127.

30 El diseño de programas urbanísticos muy acabados subrayan la majestuosidad del poder real en la ciudad palatina, la Alhambra (MALPICA CUELLO, A., "La Alhambra, ciudad palatina. Perspectivas desde la arqueología", en Arqueología y territorio medieval, 8 (2001), pp. 205-251; y del mismo autor La Alhambra de Granada, un estudio arqueológico, Granada, 2002; SALAMEH I., "Estudio de los elementos decorativos de la Puerta del Vino de La Alhambra de Granada", en Arqueología y Territorio Medieval 5 (1998), pp. 135-152, y una presencia real mucho más neta en la ciudad (a cuyo estudio específico se ha dedicado recientemente un proyecto de investigación dirigido por el profesor Malpica Cuello y titulado "La ciudad y su territorio en época nazarí", DGCYT BHA2003-00743. 2003-2006, de cuyo equipo de trabajo hemos formado parte). 
la presencia del soberano, en el epicentro de la ciudad, donde se muestra de manera más patente que en ningún otro lugar. Y no se trata solamente de un esfuerzo limitado al ámbito urbano. Los programas constructivos de fortificación fronteriza, por ejemplo, llevan implícito un mensaje de ofrecimiento de seguridad y protección que ayuda a empapar al conjunto de la sociedad nazarí de esta presencia ${ }^{31}$.

En definitiva, la sociedad nazarí está dejando de ser una sociedad islámi$\mathrm{ca}$, al menos en algunos de sus principios rectores. ¿En qué medida el "factor comercial" y los nuevos principios de organización social y económica que impone la lógica especulativa pueden participar en este proceso?

Por el momento se trata sólo de una pregunta, resuelta aún con respuestas vagas, mejor o peor definidas en su argumentación y desarrollo, pero desde luego objeto, todas ellas, de una gran proyección futura. Porque si que parece claro que efectivamente este impulso comercial que parece precipitarse gracias al apoyo exterior, puede tener repercusiones importantes sobre el conjunto de la sociedad, que se manifiestan a varios niveles.

Primero porque ayudaría a romper el equilibrio productivo de la sociedad campesina ${ }^{32}$. Se está imponiendo una demanda creciente de una serie de artículos existentes en la tradición productiva nazarí, si, pero en algunos casos y hasta ese momento de manera absolutamente secundaria. Y la necesaria ampliación de los espacios productivos dedicados a estos, supone una reorganización del espacio agrícola a costa del modelo tradicional andalusí de policultivo intensivo de regadío ${ }^{33}$, que en ningún caso permitiría fórmulas de monocultivo como las que pueden empezar a requerirse para atender a esa demanda creciente. Esas fórmulas de monocultivo no parecen llegar a imponerse en ningún momento en la práctica agrícola nazarí, pero en todo caso la ruptura del modelo agrícola tradicional puede ser una realidad en algunas zonas del reino.

El apoyo claro y explícito del Estado nazarí a todo este proceso nos ayuda a considerarlo como uno de los más importantes beneficiarios del mismo. El Estado nazarí, las élites dirigentes, incluida la familia real, no se limita a

31 MALPICA CUELLO A., "Entre la arqueología y la historia. Castillos y poblamiento en Granada. ...".

32 Cuestión ya planteada por MALPICA CUELLO A., "Il traffico commerciale nel mondo mediterraneo occidentale alla fine del Medioevo: il Regno di Granada", en ALBERINI P. (a cura di), Aspetti ed attualità del potere marittimo in Mediterraneo nei secoli XII-XVI, Roma, 1999, pp. 351-381 y posteriormente ampliada por nosotros mismos, FÁBREGAS GARCÍA, A. "La vida económica del Sultanato nazarí en su vertiente comercial", en VII Coloquio de Historia Medieval de Andalucía. Granada, 2009, pp. 81-101.

33 TRILLO SAN JOSÉ C., Agua, tierra y hombres en al-Andalus. La dimensión agrícola del mundo nazarí, Granada, 2004. 
ofrecer infraestructuras adecuadas, un tratamiento fiscal favorable o en todo caso un abrigo diplomático que proteja estas relaciones bilaterales en materia de comercio. Su apoyo se convierte en intervención desde el momento en que ellos mismos se convierten en protagonistas de esta actividad. Pasan a ser ellos mismos mercaderes, casi los únicos mercaderes nazaríes que adquieren rango internacional. Pero sobre todo desde que se convierten, en algunos casos, en los principales productores de algunos de estos artículos, que, como decimos, no tienen fácil cabida en el entorno productivo del medio rural clásico. Ponen en marcha, bajo el patrocinio real y mediante recursos como la vivificación de tierras muertas, nuevos espacios agrícolas ajenos al sistema agrario tradicional. Rastrean con ello fórmulas de aprovechamiento agrario no "traumáticas" respecto a las estructuras establecidas y que permitan hacer frente a esa demanda internacional. Sin embargo esto no parece suficiente. La sociedad nazarí, una sociedad mayoritariamente rural, tiene que verse involucrada también de un modo u otro en esta experiencia especulativa.

Pero esto no es suficiente. La sociedad nazarí, una sociedad mayoritariamente rural, se ve involucrada también de un modo u otro en el apoyo a este comercio. A pesar de las resistencia y reservas que por fuerza deben de presentar ante una experiencia completamente especulativa. Experiencia que de hecho no cumplen y que puede suponer el más importante obstáculo a progresiones posteriores.

Otra cuestión a tratar que tiene que ver no con la ruptura del equilibrio productivo, sino incluso con la ruptura del equilibrio social del medio rural. Los grandes centros rectores del comercio mantienen un radio de influencia muy activo con su entorno inmediato, con contactos de estos personajes con hombres de negocios nazaríes activos en alquerías vecinas. Estas pequeñas poblaciones rurales tienen que ver modificada de algún modo su estructura y organización social y productiva. De hecho hacia ello apunta el testimonio que el cronista portugués Gomes Eanes de Zurara nos traslada sobre una alquería vecina a Marbella a principios del siglo XV «e como quer que aquillo foie Aldea, avia alli porem muy nobres cazas; caa eram aquellos Mouros homens que tratavam com gente nobre, e que aviam riqueza, com a qual viviam em razoada policia, especialmente avia a melhor Mesquita, que se sabia em toda aquella terra .... $\gg^{34}$. A falta de un estudio pormenorizado, dejamos por el momento en suspenso una cuestión fuertemente sugestiva.

34 Gomes Eanes de ZURARA, Crónica do Comde Dom Pedro de Menezes. Ed. Facsímil de FREITAS CARVALHO J.A, Porto1988, Liv. II, cap. IX, pp. 505-515, espec. pp. 514515. 